\title{
Lexical acquisition of foreign languages by Russian native speakers
}

\author{
Natalia Viktorovna Bhatti, Olga Aleksandrovna Gorbacheva, Natalia Anatolievna Ivanova, \\ Elena Pavlovna Savchenko, and Elena Yurievna Kharitonova
}

Moscow Region State University, Department of Indo-European Languages, Moscow, Russia

\begin{abstract}
Global situation requires fluency in more than two languages nowadays. Professionals knowing several languages and aware of the lingvo-cultural aspects of global communication are of high value in the modern world due to economic, political and social - factors. Vocabulary proficiency determines an individual's mastery of the native or the second (third) language owing to the fact that lexical skills include understanding of semantics of language elements, their potential compatibility with other units and phonological characteristics of words in speech. The present research deals with the lexical characteristics of simultaneous English and German acquisition as L2 and L3 respectively by the senior students of linguistics department majoring in History and Culture of the Countries of the Studied Languages of the Institute of linguistics and cross-cultural communication of Moscow State Regional University. The authors explore the factors of mutual influence of lexical systems of both languages in the process of their study by Russian native speakers and evaluate the impact of the native language on L2 and L3 acquisition. Having analyzed the specifics of such polylingual learning environment the authors offer a method of teaching vocabulary to advanced students based on the primary importance of the native language in the second or third language acquisition. The experiment carried out within the scope of the survey proves the efficiency of the suggested technique.
\end{abstract}

Keywords: lexical acquisition, translingualism, lingvo-culture, multilingualism, language proficiency

\section{Introduction}

The study of foreign languages in the modern world is no longer a privilege of the elite. Languages are not only taught at comprehensive schools but in different language clubs and foreign language courses. In spite of this fact, qualitative language acquisition stays the main teaching target of linguistic departments of universities as before. Qualitative language acquisition does not only include mastering of communicative skills but comprises the knowledge of the system of a language and language fluency. Apart from all mentioned above the students of linguistic faculties generally study several languages

*Corresponding author: nataliebhatti@hotmail.com 
concurrently. Proficiency in English is a regular requirement in the modern world and German, French, Chinese, Spanish, Italian or Arabic are usually selected as L3 by students of linguistic departments.

The lexical system of a language is the basis for communication both in the native and in a target language. The word has phonetic and grammatical features; it is a means of thought formation and expression, since the function of processing information is a primary language function. Hence, the importance of lexical acquisition of any language is hard to overestimate.

The problem of teaching vocabulary has been studied by a number of linguists offering different perspectives on the matter from cognitive aspects of lexical acquisition to the most successful techniques of memorizing new words [1-8]. The current research covers the problems in lexical acquisition by Russian native speakers studying English and German as L2 and L3 respectively. The hypothesis is put forward that polylingual environment is utterly beneficial for the development of lexical skills of the students provided that they employ their entire linguistic repertoire when working on the lexical acquisition. The authors propose that the most effective ways of teaching vocabulary of L2 and L3 to advanced level students are based on the integration of the theory of translingualism, multiple intelligence, selection of tasks involving reflective and productive activities and materials comprising lingvo-cultural components of the target languages.

\section{$2 \quad$ Materials and methods}

The current work focuses on the lexical system of a language. Storing words in memory is a multifarious activity, comprising semantic and stylistic features of a lexeme, its acoustic representation and grammatical attributes such as morphological features, categories and syntactic functions. Thus, working on the improvement of lexical skills of advanced students it is important to remember to activate all the mentioned above aspects of a word which will help to memorize it faster and transfer it to a long-time memory $[9,10]$.

Within the scope of the present research, there has been carried out an experiment which aims at estimating the success in acquiring lexis with the help of the aforesaid integrated approach. The experiment involved 2 groups of senior students (13 students in each group) of Moscow State Regional University majoring in linguistics. The first group of students worked with a set of traditional lexical exercises: gap filling, multiple choice, word matching, etc. The students of the second (control) group were asked to read an extract form a historical adventure novel "Voyager" from the Outlander novel series by Diana Gabaldon. Then, they were to watch a corresponding extract from the film based on the novel. Finally, the control group students were asked to work with online course materials which included video fragments, texts and cartographic information about the history and culture of Scotland. The online task was to prepare an individual tour around Scotland in English, German and Russian for the convenience of tourists from different countries. All three types of tasks included the same active vocabulary and mastery of this vocabulary was tested on the final stage of the experiment. Testing of the acquisition of the active word was carried out in two stages with a four weeks' interval in between the stages to see whether the new words were settled in a short-term memory only or whether they were transferred into a long-term memory with the help of the selected types of activities.

\section{$3 \quad$ Results}


The students' progress in vocabulary acquisition was assessed with the help of 2 tests which included sentences with gaps that were to be filled in with the words or expressions form the list of the active vocabulary. The participants of the first stage of testing got 1 point for each correct active lexical item. There were 20 active words or word combinations on the list. The results of the first stage of the experiment are presented in Table1.

Table 1. Active vocabulary acquisition at the $1^{\text {st }}$ stage of assessment.

\begin{tabular}{|c|l|l|}
\hline \multicolumn{2}{|c|}{ Group 1 } & Group 2 (control group) \\
\hline $\max$ & 17 points -2 students & 20 points -4 students \\
\cline { 2 - 3 } 20 & 16 points -1 student & 19 points -2 students \\
\cline { 2 - 3 } poin & 15 points -3 students & 18 points -2 students \\
\cline { 2 - 3 } ts & 14 points -2 students & 15 points -3 students \\
\cline { 2 - 3 } & 13 points -2 students & 14 points -2 students \\
\cline { 2 - 3 } & 10 points -1 student & 12 points -1 student \\
\cline { 2 - 3 } & 9 points -2 students & \\
\hline
\end{tabular}

The results show that at the initial stage of the assessment of progress the students from the control group demonstrate a higher level of vocabulary acquisition than those students who worked with a traditional set of exercises. Firstly, 4 students from the control group managed to remember all 20 active words while the highest score of testing in the first group was equal to 17 . Secondly, all the students in the second group were able to memorize more than $50 \%$ of the active words, whereas in the first group there were 3 students who remembered $50 \%$ or all the words or less. Finally, 2 students in the first group showed the lowest percentage of vocabulary acquisition $-45 \%$.

The second stage of testing of the participants confirmed the supposition that the activities used for teaching vocabulary to the control group are more effective in terms of long-time memory as well. Four weeks after the first stage of the experiment the groups were asked to complete an online test in which the students were supposed to select the right option of the definition of the active words. For every right answer, they were given 1 point. There were 20 questions in total, which corresponded to the number of the active words and expressions. The received data are shown in Table 2.

Table 2. Active vocabulary acquisition at the $2^{\text {nd }}$ stage of assessment.

\begin{tabular}{|l|l|l|}
\hline \multicolumn{2}{|c|}{ Group 1 } & Group 2 (control group) \\
\hline $\mathrm{m}$ & 15 points -2 students & 20 points -1 student \\
\cline { 2 - 3 } $\mathrm{a}$ & 13 points -3 students & 19 points -1 student \\
\cline { 2 - 3 } $\mathrm{x}$ & 10 points -2 students & 18 points -2 students \\
\cline { 2 - 3 } 2 & 9 points -1 student & 17 points -2 students \\
\cline { 2 - 3 } 0 & 8 points -1 student & 14 points -3 students \\
\cline { 2 - 3 } $\mathrm{p}$ & 7 points -2 students & 13 points -2 students \\
\cline { 2 - 3 } $\mathrm{o}$ & 5 points -2 students & 11 points -2 students \\
\hline
\end{tabular}




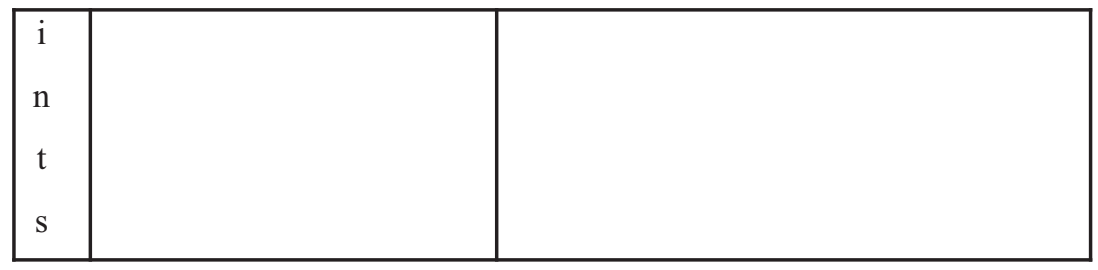

As we may see, at least one student in the control group showed a maximum score in remembering the active words (20), when the maximum of words which the first group managed to remember is 15 . All the participants of the control group kept in their memory more than $50 \%$ of the words given for acquisition. However, approximately half of the students in group 1 acquired less than $50 \%$ of the active vocabulary by the end of the experiment.

The results of testing of both groups' proficiency in the selected active vocabulary may be summarized in Figure 1.

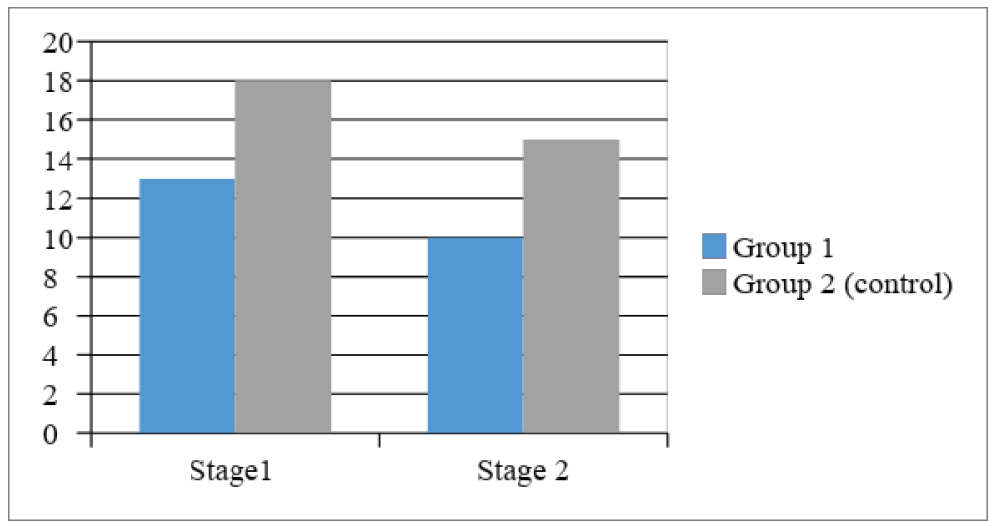

Fig. 1. Results of testing active vocabulary acquisition of Group 1 and Group 2.

As seen from the chart the total of points received by the control group at the first and at the second stage of testing is $25 \%$ higher than the score received by the group which followed regular routine of exercises which confirms the working hypothesis of this research.

\section{Discussion}

The key principles of successful lexical acquisition of L2 and L3 lie in the combination of several approaches which have to be employed in teaching students of an advanced level. Firstly, the interference of L1 on the process of L2 and L3 acquisition has to be neutralized by explaining and comparing similar and different features of the language systems. In this case, translating from L1 into L2 and then into L3 and vice-versa seems to be an essential training resource as it enables students to understand internal algorithms of functioning of lexical items by comparing them in the working languages [11-13].

Mastering the lexical system of a language is directly linked to the profound knowledge of the lingua-culture of the target language, because a word represents a concept which in its turn stands for realities of a foreign country [14]. Consequently, the second approach is the linguacultural approach which is realized through the careful selection of teaching materials in the light of their linguacultural value. Thirdly, the role of the English language 
as the world's lingua franca should be taken into account in L2 or L3 vocabulary building. It seems highly unpractical to learn lexical units strictly limited to a certain variety of English and unrecognizable outside this variety. Therefore, introduction to the culture of the native speakers of only one English variety instead of encompassing all possible cultures using English for international communication appears to be pointless.

Speaking about learning German as L3 in particular, one has to remember that in Russian learning environment German acquisition is practically always mediated by English, thus all the aspects typical of learning English will be to some extent reflected in the process of learning German $[15,16]$.

The authors of the present study find video resources the most helpful and effective in vocabulary acquisition of L2 and L3, due to the fact that video materials do not only include the meaning, phonetic and grammatical features of a lexical unit, but also contain corresponding non-verbal information which impacts visual and emotional intelligences and helps to build associations.

\section{$5 \quad$ Conclusions}

The practice of lexical acquisition adopted in childhood plays a key role in L2 and L3 vocabulary learning. L2 and L3 studying is a search of new ways of representation of an individual's knowledge about the world gained while learning the native language rather than cognition in its pure form. Thus, the use of translingual principle at the core of which lies the comparison of languages constituting the learners' repertoire seems justified, since the purpose of education at a linguistic university is bilingual language proficiency. Multilingual practices have an overall beneficial impact on the process of studying and help to make considerable progress in vocabulary acquisition.

As a rule, having reached an advanced level learners already possess a good understanding of grammatical and phonetic aspects of L2 and L3 and the focus of their attention in lexical acquisition is shifted to the internal meaning of a word, its stylistic and word-formative characteristics, its synonyms, antonyms and hyponyms. The learning of words is not intentional any longer at this stage and happens latently through different sources when learners gain knowledge on the topic interesting or important for them. The sources of information, in this case, must be as diverse as possible so that the learning environment can come as close to the natural language environment as possible. Mass media, original fiction, video films and the Internet resources should be used together to impact several types of intelligence simultaneously to achieve the desirable results.

\section{References}

1. D. Asyiah, J Bahasa Lingua Sci, 9(2), 293-318 (2017). https://doi.org/10.21274/1s.v9i2.701

2. R. Carter, Vocabulary: Applied linguistic perspectives (Routledge, London and New York, 1992)

3. E. Clark, Lexical Acquisition and the Structure of the Mental Lexicon, in Oxford Research Encyclopedia of Linguistics (2021) https://doi.org/10.1093/acrefore/9780199384655.013.96

4. A.E. Maksaeva, Sotsiokulturnyi opyt prepodavaniya angliiskogo yazyka [Sociocultural experience in English language teaching] (Flinta, Moscow, 2016) 
5. J. Mardali, Cogent Edu, 6(1) (2019). https://doi.org/10.1080/2331186X.2019.1686812

6. M. Masita, J Lang Teach Liter, 7(1), 128-135 (2020). https://doi.org/10.30605/25409190.143

7. R.P. Milrud, Teoriya prepodavaniya inostrannykh yazykov [The theory of foreign languages teaching] (Urait, Moscow, 2019)

8. A. Susanto, J KATA, 1(2), 182-191 (2017). https://doi.org/10.22216/jk.v1i2.2136

9. V. Dronjic, The CATESOL J, 31, 29-54 (2019)

10. S.E. Kusmaryati, PROMINENT J, 1(1), 21-36 (2018)

11. E. Chung, Asia-Pacific Edu Res, 27, 499-508 (2018)

12. O.E.H. Elmahdi, A.M.M. Hezam, Adv Soc Sci Res J, 7(5), 556-575 (2020). https://doi.org/10.14738/assrj.75.8263

13. A. Karami, F.A. Bowles, Austral J Teach Edu, 44(9) (2019). http://dx.doi.org/10.14221/ajte.2019v44.n9.2

14. S.G. Ter-Minasova, Yazyk i mezhkulturnaya kommunikatsiya [Language and intercultural communication] (Moscow State University Press, Moscow, 2004)

15. A.V. Gizatullina, et al., Inostrannye yazyki v shkole: izuchenie nemetskogo yazyka posle angliiskogo [Foreign languages at school: learning German after English] (Kazan State University press, Elabuga, 2016)

16. G. Mehlhorn, Lebenslanges Lernen und Mehrsprachigkeit: Deutsch als Fremdsprache nach Englisch im russischsprachigen Kontext [Lifelong learning and multilingualism: German as a foreign language after English in a Russian-speaking context], in Das Wort. Germanistisches Jahrbuch, 177-193 (DAAD, Moscow, 2012) 